\title{
Goal effectiveness after players' dismissals in professional futsal teams
}

\section{Miguel A. Gómez, César Méndez, Alejandro Indaburu \& Bruno Travassos}

To cite this article: Miguel A. Gómez, César Méndez, Alejandro Indaburu \& Bruno Travassos (2018): Goal effectiveness after players' dismissals in professional futsal teams, Journal of Sports Sciences, DOI: 10.1080/02640414.2018.1531498

To link to this article: https://doi.org/10.1080/02640414.2018.1531498

$$
\text { 曲 Published online: } 13 \text { Oct } 2018 .
$$

6 Submit your article to this journal $\square$

$$
\text { View Crossmark data } ₫
$$




\title{
Goal effectiveness after players' dismissals in professional futsal teams
}

\author{
Miguel A. Gómez (10), César Méndez (10) ${ }^{\mathrm{a}}$, Alejandro Indaburu ${ }^{\mathrm{a}}$ and Bruno Travassos (10 ${ }^{\mathrm{b}}$ \\ aPhysical Activity and Sport Sciences, Technical University of Madrid, Madrid, Spain; ${ }^{b}$ CIDESD, Research Center in Sports Sciences, Health Sciences \\ and Human Development, Department of Sport Sciences, University of Beira Interior, Covilhã, Portugal
}

\section{ABSTRACT}

The purpose of this study was to analyse the effect of players' dismissals on the outcome of attacks in elite futsal matches, and to establish the performance profile of the attacks made in numerical superiority by elite futsal teams. One hundred and twenty five attacking game situations in numerical superiority (dismissal of opponents from defensive team) were analysed from the regular season of the Spanish professional Futsal League. The effect of contextual-related variables (quality of opposition, match-location, match-periods, opponent team's fouls, match-status, attack-duration and match-type) on goal effectiveness was analysed using binomial logistic regression and two-step cluster analysis. Results from the binary logistic regression showed that the highest attack effectiveness was achieved when the teams play at home, perform the attack during minutes 33-36 and the opposing team has 3 fouls. Secondly, the two-step cluster analysis technique allowed identifying four types of attacks when the teams were playing with numerical superiority. The results showed the great importance (in order) of match-type, match-status, attacking team's fouls, match-period, quality of opposition, opposing team's fouls, match-location, goal situation, and attack duration. The identified trends may help coaches to design the superiority/inferiority scenarios more specifically during training and to monitor them during competition.
ARTICLE HISTORY

Accepted 6 September 2018

\section{KEYWORDS}

Indoor soccer; dismissal; situational variables

\section{Introduction}

Futsal is a team sport organised and regulated by the FIFA (Fédération Internationale de Football Association) that has grown rapidly since the standardisation of protocols and guidelines on international competitions (Castagna, D'Ottavio, Vera, \& Álvarez, 2009; Vicente-Vila \& Lago-Peñas, 2016). Regardless of its rising popularity, the available scientific data is limited and even more so if it is compared with other team sports such as football, basketball, water polo or handball (Beato, Coratella, \& Schena, 2016; Gomez, Moral, \& Lago-Peñas, 2015; Sarmento et al., 2014).

Futsal could be considered an intermittent high speed dynamic sport that involves quick actions (i.e., multiple sprints) with incomplete active and passive pauses (Barbero-Alvarez, Soto, Barbero-Alvarez, \& Granda-Vera, 2008). Due to the unlimited amount of substitutions, the intensity and pace of the game are continuously high and do not decrease during the match (Castagna et al., 2009). Moreover, the restrictions and constant variations in space and time require precise contextdependent individual actions and collective moves (Travassos et al., 2016). Consequently, higher levels of coordination between players and teams (tactical behaviour) are required in order to manage the space and perform successfully (Travassos, Araújo, Duarte, \& McGarry, 2012).

Particularly in futsal, the game can be played with unbalanced numerical relations under two conditions; with clear implications for opportunities to change the game result (Leão, 2010) and tactical behaviour of players and teams
(Corrêa, Davids, Silva, Denardi, \& Tani, 2014; Travassos, Vilar, Araújo, \& McGarry, 2014). The attacking team can play with a numerical advantage when the goalkeeper is substituted for an extra outfield player (5-v-4+ GK) or when an opponent is dismissed from the match after receiving two yellow cards or a direct red card (Gk+ 4-v-3+GK). While the first condition is the result of a coach strategy to change playing dynamics, the second is due to game dynamics according to the rules. Ferreira-da Silva (2011) found that most of the cases of unbalanced numerical relations (5-v-4+ GK or Gk+ 4-v-3+ GK) occur during the second half of the match, specifically during the last 10 minutes, with a high probability of changing the game result.

When a player is sent off the team has to play with one less player for a maximum of two minutes. If this team concedes a goal before the end of those two minutes, another player goes onto the pitch to replace the one dismissed, who is not allowed to return to the match (FIFA, 2014/2015, rule 3). As previously mentioned, a player's exclusion may influence the tactical behaviour of players and teams and also the game result. During the period of exclusion an increase of goals scored was observed that may create a negative state for the team with the player down and then affect the game result. Numerical unbalance may force the team in numerical inferiority to adopt a zone defence strategy, similar to the one adopted when playing against a team that uses the $5-\mathrm{v}-4+\mathrm{GK}$ strategy (Corrêa et al., 2014). Thus, this two minute (or less) numerical disadvantage is supposed to produce more goal 
occasions for the opposing team and at least one goal before the fifth player returns to the game. Previous research showed that most of the goals were scored within the next 2-min after the exclusion during the last 10-min of the matches. In fact, this numerical superiority condition was clearly positive for the opposing team (Leão, 2010). Also, in handball, Prieto, Gómez, and Sampaio (2015) showed that players' dismissals improve the score of teams with a numerical advantage. Lupo, Tessitore, Minganti, and Capranica (2010) in water polo stated that the highest percentage of goals scored occurred in power play situations, that is when a player commits an exclusion foul and the team has to play 20s in numerical inferiority.

Lago-Peñas, Gómez-Ruano, Owen, and Sampaio (2016) studied team performance after a dismissal in 11-a side football (five Elite professional European Leagues). Their results showed better performances for the team with numerical superiority (11 vs. 10) in time spent in possession, successful passes, touches or short passes than during balanced situations.

However, despite the high probability of a goal being scored by the team with numerical advantage during the exclusion penalisation of the defending team, the available literature related to this moment of the game in futsal is scarce. According to Sarmento, Bradley, and Travassos (2015) one important way to improve the understanding of the game is to identify and analyse each moment of the game and the correspondent strategies used by coaches to successfully perform in each one. Also, there is a need to identify the contextual variables that constrain the outcome of attacks in elite futsal matches, to improve coaches' interventions during these periods and to adjust training sessions to be more representative of game demands (creation, control and definition of strategies for specific training scenarios that occur in competition). This approach would contribute to improving the understanding of game dynamics and strategies in different dismissal match scenarios. Therefore, the purpose of this study was two-fold: i) to analyse the effect of players' dismissals on the outcome of attacks in elite futsal matches; and ii) to establish a performance profile of the attacks in superiority developed by elite futsal teams. In line with previous research, it could be expected that during the $2 \mathrm{~min}$ of numerical advantage the teams increase the shots on target situations, especially during the last moments of the match, and that the use of longer possessions allows higher effectiveness in attack. Finally, it was expected that different game profiles could be identified with varying values of effectiveness in dismissal scenarios.

\section{Method}

\section{Sample}

The sample was composed of all the attack situations when the opponents suffered a dismissal during the matches from the regular season of the Spanish professional Futsal League (2014-2015 season). One hundred and twenty nine attack situations were gathered from 39 matches. Four attacks were excluded from the sample, due to the fact that the goalkeeper was used as an outfield player during the dismissal numerical superiority (5-v-3+ GK). Thus, 125 attacks that involved numerical superiority Gk+ 4-v-3+ GK were analysed (The sample included at least 2 attacks of each team of the league). The mean number of attacks played during the 2 min of numerical superiority was $3.18 \pm 2.1$ (39 dismissals during 240 matches, and only one match included two dismissals).

\section{Procedure}

The matches were analysed through systematic observation using the official league video analysis software (Astrofutsal ${ }^{\circledR}$, www.http://astrofutsal.wixsite.com/astro-sport). Two experienced observers (graduates in Sports Sciences with 12 years experience as futsal coaches and performance analysts) were trained for this task. Twenty percent of the actions studied were randomly selected and re-observed to test data reliability ( $n=26$ attacks). The weighted Kappa correlation coefficients results showed very good kappa values for both observers for intra-observer and inter-observer reliability (Kappa values greater than 0.88, very good values) (Altman, 1991).

\section{Data notation}

The attack situations were transformed into a dichotomous dependent variable (Goal/No goal) due to the fact that all the 125 attacks ended with a shot, then the effectiveness of each attack situation was not considered as in previous studies (Gómez et al., 2015).

The independent variables were related to contextualrelated variables (Gómez, Lorenzo, Ibáñez, \& Sampaio, 2013; Marcelino, Mesquita, \& Sampaio, 2011): (i) Quality of Opposition (QO) was measured as the end-of-season ranking differences between the two teams (QO = Rank team A - Rank team B). Then, the variable was split into three categories of confrontation according to the attacking team: a) better than the opponent (4 or more ranking points than the opponent); b) balanced confrontation (differences between 3 and -3 ranking points); and c) worse than the opponent (4 or more ranking points lower than the opponent); (ii) Match location (playing at home or away); (iii) Match periods (the match time was split into 10 periods of 4 min); (iv) Attacking team's fouls ( 0 to 5 fouls committed); (v) Opponent team's fouls ( 0 to 5 fouls committed); (vi) Match Status: the score differences when the dismissal occurred were considered as winning, drawing or losing conditions; (vi) Attack duration: using a $k$-means cluster analysis to differentiate all attacks in three groups according to the duration: a) short attacks (range 1-23s, mean $=14.14 \pm 5.49$ ); b) medium duration attacks (range 24-56s, mean $=34.06 \pm 9.16$ ); and c) long attacks (range 57-107s, mean $=68.25 \pm 14.72$ ); and (vii) Match Type: the matches were split according to final score differences $(k$ means cluster) as balanced (ranging between a 0 to 2 goal difference) or unbalanced matches (more than a 2 goal difference).

\section{Statistical analysis}

Firstly, a descriptive and inferential analysis was performed using Crosstab Commands. Pearson's Chi-square test was used to analyse the effects between attack outcome (Goal/ 
no goal) and the contextual-related variables. Effect sizes (ES) were calculated using Cramer's $V$ test and their interpretation was based on the following criteria: $0.10=$ small effect, $0.30=$ medium effect, and $0.50=$ large effect (Volker, 2006).

Secondly, a binary logistic regression was used to assess the relationship between contextual-related variables according to attack effectiveness. The dependent variable used in the model was $Y \subset\{0,1\}$, with 0 (1) values for no goal (goal) attack (Willoughby, 2002). Then, the binomial logistic regression model can be expressed as follows:

$$
E(Y / X)=\frac{e^{(Z)}}{1+e^{(Z)}}
$$

Where $\mathrm{Z}$ represents $=\beta 0+\beta 1 * \mathrm{QO}+\beta 2 * \mathrm{ML}+\beta 3 * \mathrm{MP}$

$$
+\beta 4 * \mathrm{AF}+\beta 5 * \mathrm{OF}+\beta 6 * \mathrm{MS}+\beta 7 * \mathrm{AD}+\beta 8 * \mathrm{MT}+\varepsilon \mathrm{i}
$$

$\beta 0$ is the constant of the equation, and the independent variables were $\mathrm{QO}=$ Quality of Opposition, $\mathrm{ML}=$ Match Location, $M P=$ Match Period, AF = Attacking team's Fouls, OF = Opponent's Fouls, MS = Match Status, AD = Attack Duration; MT = Match Type; $\varepsilon i=$ is the disturbance term.

The binary logistic regression model is a nonlinear technique that estimates the regression coefficients that account for the estimated change in the log-odds, corresponding to a unit change in the corresponding explanatory variable conditional and the other explanatory variables remaining constant (Landau \& Everitt, 2004). The Odds ratios (OR) and their 95\% confidence intervals $(\mathrm{Cl})$ were also determined.

Finally, a two-step cluster with log-likelihood as the distance measure and Schwartz's Bayesian criterion was performed in order to classify the type of attacks according to the variables studied. This method differs from traditional clustering techniques by automatically determining the optimal number of clusters and scalability (Tabachnick \& Fidell, 2007). The variables were ranked according to the predictor's importance, providing normalised weights to support the cluster distribution. Then the percentage that each attack appears in the obtained clusters was computed. In a second step, the clusters were differentiated according to attack effectiveness using the Crosstab Command. All the statistical analyses were performed using IBM SPSS statistics for Windows, version 20.0 (Armonk, NY: IBM. Corp.) and the significance level was set at $p<0.05$.

\section{Results}

The sample distribution of each contextual-related variable is presented in Table 1 (percentage and case numbers). The results showed that attack duration was significant $\left(\mathrm{x}_{2}{ }^{2}=11.06\right.$; $p=0.003$ ) with lower effectiveness when playing short attacks ranging between 1-23s and higher effectiveness when playing attacks ranging between 24-56s. No significant relationships were identified between attack effectiveness and the rest of the contextual-related variables.

Results from the binary logistic regression analysis (Table 2), showed a significant model $\left(x_{26}^{2}=55.75 ; p=0.001 ; R^{2}=0.57\right)$ with the strong influence of match location (LRT $=7.55, \mathrm{df}=1$, $P=0.006)$, match period (LRT $=13.09$, $\mathrm{df}=9, P=0.049$ ), opponent team's fouls (LRT $=3.76, \mathrm{df}=5, P=0.048$ ), match type
Table 1. Frequency distribution (\%) of attack effectiveness in superiority according to contextual-related variables (Crosstab Command: Pearson's Chi-square,

\begin{tabular}{|c|c|c|c|c|c|c|c|c|}
\hline \multirow[b]{3}{*}{ Variables } & \multicolumn{4}{|c|}{$\begin{array}{c}\text { Attack } \\
\text { Effectiveness }\end{array}$} & \multirow[b]{3}{*}{$x^{2}$} & \multirow[b]{3}{*}{$P$} & \multirow[b]{3}{*}{ EFD } & \multirow[b]{3}{*}{ ES } \\
\hline & \multicolumn{2}{|c|}{ No goal } & \multicolumn{2}{|c|}{ Goal } & & & & \\
\hline & $\%$ & $\bar{n}$ & $\%$ & $\mathrm{n}$ & & & & \\
\hline \multicolumn{9}{|c|}{ Quality of Opposition } \\
\hline $\begin{array}{l}\text { Better than the } \\
\text { opponent }\end{array}$ & 33.0 & 33 & 36.0 & 9 & & & & \\
\hline $\begin{array}{l}\text { Balanced with the } \\
\text { opponent }\end{array}$ & 47.0 & 47 & 56.0 & 14 & 1.93 & 0.39 & $4.40 \dagger$ & 0.12 \\
\hline $\begin{array}{l}\text { Worse than the } \\
\text { opponent }\end{array}$ & 20.0 & 20 & 8.0 & 2 & & & & \\
\hline \multicolumn{9}{|l|}{ Match Location } \\
\hline Home & 52.0 & 52 & 72.0 & 18 & 3.25 & 0.06 & 11.0 & 0.16 \\
\hline Away & 48.0 & 48 & 28.0 & 7 & & & & \\
\hline \multicolumn{9}{|c|}{ Attacking team's fouls } \\
\hline 0 & 1.0 & 1 & 12.0 & 3 & & & & \\
\hline 1 & 31.0 & 31 & 32.0 & 8 & & & & \\
\hline 2 & 8.0 & 8 & 8.0 & 2 & 6.85 & 0.20 & $0.80 \dagger$ & 0.26 \\
\hline 3 & 18.0 & 18 & 12.0 & 3 & & & & \\
\hline 4 & 18.0 & 18 & 20.0 & 5 & & & & \\
\hline 5 & 24.0 & 24 & 16.0 & 4 & & & & \\
\hline \multicolumn{9}{|c|}{ Opposing team's fouls } \\
\hline 0 & 13.0 & 13 & 12.0 & 3 & & & & \\
\hline 1 & 30.0 & 30 & 12.0 & 3 & & & & \\
\hline 2 & 8.0 & 8 & 12.0 & 3 & & & & \\
\hline 3 & 6.0 & 6 & 16.0 & 4 & 6.82 & 0.20 & $2.00 \dagger$ & 0.23 \\
\hline 4 & 10.0 & 10 & 4.0 & 1 & & & & \\
\hline 5 & 33.0 & 33 & 44.0 & 11 & & & & \\
\hline \multicolumn{9}{|l|}{ Match Status } \\
\hline Winning & 40.0 & 40 & 60.0 & 15 & & & & \\
\hline Drawing & 14.0 & 14 & 20.0 & 5 & 5.91 & 0.53 & $3.80 \dagger$ & 0.06 \\
\hline Losing & 46.0 & 46 & 20.0 & 5 & & & & \\
\hline \multicolumn{9}{|l|}{ Attack Duration (s) } \\
\hline $1-23 s$ & 68.0 & 68 & 32.0 & 8 & & & & \\
\hline $25-56 s$ & 30.0 & 30 & 64.0 & 16 & 11.1 & $0.01^{* *}$ & $0.60 \dagger$ & 0.29 \\
\hline $57-107 s$ & 2.0 & 2 & 4.0 & 1 & & & & \\
\hline \multicolumn{9}{|l|}{ Match period } \\
\hline 2 & 0.0 & 0 & 4.0 & 1 & & & & \\
\hline 3 & 3.0 & 3 & 0.0 & 0 & & & & \\
\hline 4 & 5.0 & 5 & 8.0 & 2 & & & & \\
\hline 5 & 14.0 & 14 & 8.0 & 2 & 10.5 & 0.17 & $0.20 \dagger$ & 0.30 \\
\hline 6 & 22.0 & 22 & 8.0 & 2 & & & & \\
\hline 7 & 2.0 & 2 & 4.0 & 1 & & & & \\
\hline 8 & 9.0 & 9 & 8.0 & 2 & & & & \\
\hline 9 & 7.0 & 7 & 20.0 & 5 & & & & \\
\hline 10 & 38.0 & 38 & 40.0 & 10 & & & & \\
\hline \multicolumn{9}{|l|}{ Match Type } \\
\hline Balanced & 69.0 & 69 & 56.0 & 14 & & & & \\
\hline Unbalanced & 31.0 & 31 & 44.0 & 11 & 1.51 & 0.22 & 8.40 & 0.11 \\
\hline
\end{tabular}
significance, expected frequency distribution, and effect size).

${ }^{*} P<0.05$, ${ }^{* *} \mathrm{P}<0.01$; EFD = expected frequency distribution; + When EFD was below 5 or the variable includes values below $1 \%$ the Fisher's exact test was applied.

(LRT $=5.38, \mathrm{df}=1, P=0.02)$, and attack duration (LRT $=16.98$, $\mathrm{df}=2, P<0.001)$. The highest attack effectiveness was achieved when the teams played at home $(O R=65.1)$, performed the attack in match period $9(\mathrm{OR}=18.41)$, and the opponent team had 3 fouls (OR $=63.0$ ) (Table 2). However, the attack effectiveness decreased when teams used attack durations of 1-23s $(O R=0.03)$ and during balanced matches $(O R=0.09)$.

The two-step cluster analysis technique allowed identification of four types of attacks when the teams were playing in conditions of numerical superiority (an opponent's dismissal). Table 3 includes the information for each cluster and the importance of each variable in the model and for each cluster. The results showed the great importance (in order) of match type, match status, attacking team's fouls, match period, quality of opposition, opponent team's fouls, match location, goal 
Table 2. Results of attack effectiveness in superiority as a function of contextual-related variables used by futsal teams.

\begin{tabular}{|c|c|c|c|c|c|c|c|c|}
\hline \multirow[b]{2}{*}{ Variables } & \multirow[b]{2}{*}{ B } & \multirow[b]{2}{*}{ S.E. } & \multirow[b]{2}{*}{ Wald } & \multirow[b]{2}{*}{ df } & \multirow[b]{2}{*}{ Sig. } & \multirow[b]{2}{*}{$\operatorname{Exp}(B)$} & \multicolumn{2}{|c|}{ 95\% C.I. $\operatorname{EXP}(B)$} \\
\hline & & & & & & & Lower & Upper \\
\hline \multicolumn{9}{|l|}{ Quality of Opposition (a) } \\
\hline Better than the opponent & -0.31 & 2.15 & 0.02 & 1 & 0.89 & 0.73 & 0.01 & 49.93 \\
\hline $\begin{array}{l}\text { Balanced with the opponent } \\
\text { Match Location (b) }\end{array}$ & -0.12 & 1.87 & 0.00 & 1 & 0.95 & 0.89 & 0.02 & 34.62 \\
\hline Home & 4.18 & 1.69 & 6.07 & 1 & $0.01^{* *}$ & 65.11 & 2.35 & 1803.37 \\
\hline \multicolumn{9}{|l|}{ Match period (c) } \\
\hline 2 & 18.28 & 0.00 & & 1 & & 9.16 & 59.16 & \\
\hline 3 & -17.7 & 21.02 & 0.00 & 1 & 1.00 & 0.40 & 0.00 & 1735.01 \\
\hline 4 & 0.51 & 3.57 & 0.02 & 1 & 0.89 & 1.66 & 0.00 & 1816.02 \\
\hline 5 & 1.35 & 1.87 & 0.52 & 1 & 0.47 & 3.87 & 0.10 & 151.64 \\
\hline 6 & -1.89 & 1.42 & 1.77 & 1 & 0.18 & 0.15 & 0.01 & 2.45 \\
\hline 7 & -1.17 & 4.69 & 0.06 & 1 & 0.80 & 0.31 & 0.00 & 3012.60 \\
\hline 8 & 0.20 & 2.29 & 0.01 & 1 & 0.93 & 1.22 & 0.01 & 108.54 \\
\hline 9 & 2.91 & 1.38 & 4.45 & 1 & $0.03^{*}$ & 18.41 & 1.23 & 275.44 \\
\hline \multicolumn{9}{|l|}{ Attacking team's fouls (d) } \\
\hline 0 & 3.80 & 3.36 & 1.28 & 1 & 0.26 & 44.79 & 0.06 & $32,469.30$ \\
\hline 1 & 0.45 & 1.42 & 0.10 & 1 & 0.75 & 1.57 & 0.10 & 25.34 \\
\hline 2 & 1.28 & 1.94 & 0.43 & 1 & 0.51 & 3.58 & 0.08 & 162.02 \\
\hline 3 & -2.29 & 1.75 & 1.72 & 1 & 0.19 & 0.10 & 0.00 & 3.10 \\
\hline 4 & 0.08 & 1.76 & 0.00 & 1 & 0.96 & 1.08 & 0.03 & 34.00 \\
\hline \multicolumn{9}{|l|}{ Opposing team's fouls (e) } \\
\hline 0 & 3.56 & 2.14 & 2.77 & 1 & 0.10 & 35.29 & 0.53 & 2353.80 \\
\hline 1 & 2.68 & 1.74 & 2.37 & 1 & 0.12 & 14.62 & 0.48 & 444.00 \\
\hline 2 & -0.13 & 1.59 & 0.01 & 1 & 0.93 & 0.88 & 0.04 & 19.60 \\
\hline 3 & 4.14 & 2.07 & 3.99 & 1 & $0.04^{*}$ & 63.04 & 1.08 & 3679.48 \\
\hline 4 & -0.63 & 1.86 & 0.11 & 1 & 0.74 & 0.53 & 0.01 & 20.64 \\
\hline \multicolumn{9}{|l|}{ Match Status (f) } \\
\hline Winning & 1.84 & 1.25 & 2.19 & 1 & 0.14 & 6.32 & 0.55 & 72.77 \\
\hline Drawing & 1.69 & 1.57 & 1.16 & 1 & 0.28 & 5.42 & 0.25 & 117.14 \\
\hline \multicolumn{9}{|l|}{ Attack Duration (g) } \\
\hline $1-23 s$ & -3.60 & 1.12 & 10.26 & 1 & $0.01^{* *}$ & 0.03 & 0.00 & 0.25 \\
\hline $57-107 s$ & -2.78 & 1.97 & 2.00 & 1 & 0.16 & 0.06 & 0.00 & 2.94 \\
\hline \multicolumn{9}{|l|}{ Match Type (h) } \\
\hline Balanced & -2.41 & 1.15 & 4.42 & 1 & $0.04^{*}$ & 0.09 & 0.01 & 0.85 \\
\hline Intercept & -3.58 & 2.25 & 2.52 & 1 & 0.11 & & & \\
\hline
\end{tabular}

situation, and attack duration. Each cluster shows specific profiles of attack contexts: (a) cluster 1 was characterised by $77.8 \%$ of no goal actions. The team was winning an unbalanced match, playing away, during match period 10 , and the attacking team was better than the opponent; (b) cluster 2 was the least effective with $100 \%$ no goal. The team was playing a balanced match, playing away, losing, using short attacks (1-23s) and the attacking team was better than the opponent; (c) cluster 3 is the most effective with $55.9 \%$ no goal. The team was playing at home an unbalanced match, against a balanced opponent, during match period 10 and using short attacks; (d) lastly, cluster 4 was characterised by $86.2 \%$ of no goal actions. The team was playing at home against a balanced opponent with a losing match status, using short attacks during match period 6 and the opponent had 4 team fouls.

The results comparing these four clusters according to the goals scored are presented in Table 4. The attack type (clusters) were significant according to goal effectiveness showing that cluster 2 was the most negative (100\% of no goal situations) and that cluster 3 was the most positive $(55.9 \%$ of no goal situations).

\section{Discussion}

The first aim of this study was to identify the effect of players' exclusions on teams' attacking performance in professional futsal. As argued, coaches try to identify the strengths and weaknesses of their opponents from a collective point of view as a way to control and manage their strategies and tactics during the match (Sarmento et al., 2015). Thus, the analysis of the attacks in superiority in elite futsal matches integrating the contextual-related variables (quality of opposition, match location, match period, attacking team's fouls, opponent's fouls, match status, attack duration and match type) made it possible to determine their effectiveness on the match outcome.

The overall result revealed that when a player was dismissed, the opponent's team has a $100 \%$ chance of shooting on goal and a mean of 3.18 attack actions during the 2-min period. According to the rationale of the present study, the current findings are consistent with the first hypothesis established due to an increase of shot on target behaviours (Corrêa et al., 2014; Leão, 2010). These results could be consistent with the need to change the tactical behaviour of players and teams adopting a zone defence (Corrêa et al., 2014). As mentioned by Vilar, Araujo, Davids, Correia, and Esteves (2013), the numerical disadvantage of a defending team increases the distance of defenders to passing and shooting lines, increasing the passing and shooting opportunities of the attacking team. In addition, the percentage of goals scored from those 125 attacks was $20 \%$. This result is not as high as could be anticipated, mostly due to a multitude of factors and psychological components such as criticality, anxiety, stress or choking, which may lead to a 
Table 3. Information on each contextual-related variable according to the obtained cluster.

\begin{tabular}{|c|c|c|c|c|}
\hline Cluster & 1 & 2 & 3 & 4 \\
\hline Size & $21.6 \% ; n=27$ & $28.0 \% ; n=35$ & $27.2 \% ; n=34$ & $23.2 \% ; n=29$ \\
\hline MT $(I=1.0)$ & Unbalanced & Balanced & Unbalanced & Balanced \\
\hline MS $(I=0.93)$ & $85.2 \%$ & $80.0 \%$ & $82.4 \%$ & $58.6 \%$ \\
\hline \multirow[t]{2}{*}{$\mathrm{AF}(\mathrm{I}=0.82)$} & $33.3 \%$ & $45.7 \%$ & $33.3 \%$ & $82.8 \%$ \\
\hline & 3 Fouls & 4 Fouls & 1 Foul & 1 Foul \\
\hline MP $(I=0.79)$ & $55.6 \%$ & $62.9 \%$ & $32.4 \%$ & $41.4 \%$ \\
\hline $\mathrm{QO}(I=0.79)$ & Better than the opponent & Better than the opponent & Balanced with the opponent & Balanced with the opponent \\
\hline \multirow{2}{*}{$\mathrm{OF}(\mathrm{I}=0.72)$} & $33.3 \%$ & $37.1 \%$ & $76.5 \%$ & $37.9 \%$ \\
\hline & 1 Foul & 1 Foul & 5 Fouls & 5 Fouls \\
\hline \multirow[t]{2}{*}{$M L(I=0.68)$} & $92.6 \%$ & $54.3 \%$ & 100 & $62.1 \%$ \\
\hline & Away & Away & Home & Home \\
\hline \multirow[t]{2}{*}{ Goal $(I=0.07)$} & $77.8 \%$ & $100 \%$ & $55.9 \%$ & $86.2 \%$ \\
\hline & No goal & No Goal & No goal & No goal \\
\hline
\end{tabular}

Note = I: importance of each variable in the model: MT: Match Type; MS: Match Status; AF: attacking team's fouls; MP: Match Period; QO: Quality of Opposition; OF: Opposing team's fouls; ML: Match Location; AD: Attack duration.

Table 4. Frequency distribution (\%) of attack effectiveness in superiority according to attacking clusters (Crosstab Command: Pearson's Chi-square, significance, expected frequency distribution, and effect size).

\begin{tabular}{|c|c|c|c|c|c|c|c|c|}
\hline \multirow[b]{3}{*}{ Attacking clusters } & \multicolumn{4}{|c|}{ Attack Effectiveness } & \multirow[b]{3}{*}{$x^{2}$} & \multirow[b]{3}{*}{$\mathrm{P}$} & \multirow[b]{3}{*}{ EFD } & \multirow[b]{3}{*}{ ES } \\
\hline & \multicolumn{2}{|c|}{ No goal } & \multicolumn{2}{|c|}{ Goal } & & & & \\
\hline & $\%$ & $\mathrm{n}$ & $\%$ & $\mathrm{n}$ & & & & \\
\hline 1 & $77.8 \%$ & 21 & $22.2 \%$ & 6 & & & & \\
\hline 2 & $100 \%$ & 35 & $0.0 \%$ & 0 & & & & \\
\hline 3 & $55.9 \%$ & 19 & $44.1 \%$ & 15 & 23.3 & $0.001 *$ & $5.40 \dagger$ & 0.42 \\
\hline 4 & $86.2 \%$ & 25 & $13.8 \%$ & 4 & & & & \\
\hline
\end{tabular}

${ }^{*} \mathrm{P}<0.001 ; \mathrm{EFD}=$ expected frequency distribution; + When EFD was below 5 or the variable includes values below $1 \%$ the Fisher's exact test was applied.

significant drop in performance during pressure conditions where a positive performance is expected (Hill \& Shaw, 2013; Prieto et al., 2015).

The distribution of each contextual-related variable revealed the effect of the attack duration variable with an effectiveness of $64.0 \%$ when playing duration attacks ranged from 24-56s but not with attacks lasting 1-23s (32.0\% goal). These findings are in accordance with the hypothesis established of a longer use of ball possessions (more passes and touches of the ball) when playing numerical superiority attacks (Lago-Peñas et al., 2016). Additionally, these possession durations are in accordance with Gómez et al. (2015) who identified higher effectiveness during set plays that used more than 4 passes and negative effects in set plays that used less than 4 passes. These results are similar to the current study due to the superiority during attacks involving more players and then more spaces to create open shots and clear ending situations. In fact, the defending team reduces the space to play close to the goal (i.e., conservative defensive formation) forcing the attacking team to use careful explorations of collective attacks (i.e., more passes and time duration) that involve flexible strategies to move the ball using more triangular passing behaviours or extra passes trying to obtain open players and clear positions (Travassos et al., 2016). As Gómez et al. (2015) argued, the probability of successful ball possessions in elite futsal is dependent on the defensive formation of the opposition during set plays. Thus, the results reinforce the attacking team's adaptations to the change of the defensive systems of the opponents during inferiority scenarios (Travassos et al., 2017).

The results of the binary logistic regression analysis showed the highest effectiveness for the context of a player being excluded when playing at home, in period 9 of the game, and when the opponent has 3 fouls. On the contrary, the effectiveness decreases when playing balanced matches with possession durations ranging from 1-23s. Firstly, match location is an important variable that explains effectiveness of unbalanced numerical situations $(72.0 \%$ of effectiveness when playing at home than away $28.0 \%$ ). In contrast, Vicente and Lago (2016 in their study about the goalkeeper's influence on ball possession effectiveness in futsal found that match location and match status did not indicate any impact on ball possession effectiveness. The same trend was found by Gómez et al. (2015) when they analysed ball possession effectiveness during playoff matches of the Spanish Futsal League. This finding may reflect that the match location effect is not a regular constraint throughout the match and may influence attack effectiveness in a different way according to the match context and the moments of the match analysed. According to Oliveira, Gómez, and Sampaio (2012) this variable is time- and opponent-dependent during a match, especially during and after critical incidents or in the last moments of the match (match periods 9 or 10). Then, the away team may be negatively influenced when defending in numerical inferiority against the home team that tries to score a goal during the 2-min period. In fact, this period can be considered as a psychological phase where home players were positively influenced by the crowd support, reveal better team cohesion to create open situations, and maintain better equilibrium on the field due to the familiarity with the court and the visual-spatial references (Bray, Jones, \& Owen, 2002).

Secondly, these results can be associated with the progression of game fatigue that reduces a player's physical, technical and decision-making skills as the match goes on (Prieto et al., 2015). At the end of the matches there is a critical influence of stress and pressure that may generate poor decisions and an 
increased level of aggressiveness that ends with a dismissal (Bar-Eli \& Tractinsky, 2000). In addition, the importance of playing a balanced match with 3 fouls may explain the criticality of the moment where each foul counts and have a direct effect on the team's performance. In fact, if a defending team plays the 2-min in inferiority with 3 team fouls it is forced to play with less aggression and pressure than it would do without this limitation. This context reduces the space of play and the individual aggressiveness to pressure the ball. Therefore, the use of set plays that: (i) maintain ball possession; (ii) increase the density of passes between players; and (iii) is associated with creating open spaces instead of being dependent on a specific player, increases effectiveness due to more flexible tendencies and betweenness centrality (Sarmento et al., 2016; Travassos et al., 2017).

The second aim of the study was to establish a performance profile of attacks in numerical superiority by the elite futsal teams. This analysis is of great relevance due to the importance of coaches identifying and replicating real match scenarios during training (Sarmento et al., 2015). In fact, the two-step cluster analysis showed four types of attacks during situations of numerical superiority accepting the hypothesis of the study as it was expected to identify different game profiles with varying values of effectiveness in dismissal scenarios. The main findings presented cluster 3 as the most effective $(55.9 \%$ of no goals scored) when playing an unbalanced match at home, winning the game against a balanced opponent, during match period 10, using short attacks (1-23s); and cluster 2 was considered the least effective when losing the game, playing a balanced match away, with the attacking team being better than the opponent, using short attacks, during period 10 and never scoring a goal (100\% no goals scored). In addition, clusters 1 and 4 were identified as having intermediate profiles. Specifically, the current findings reflect the basis of prediction models, such as clustering techniques, trying to identify repeatable team performances during specific events; and then to anticipate the behaviours that may occur during the match (Sarmento et al., 2016).

\section{Conclusions}

In conclusion, the analysis of goal effectiveness during players' dismissals showed the importance of contextual-related variables to constrain team behaviour and performance. Such information is extremely relevant for coach intervention and definition of game strategies during the game. In particular, the Spanish Futsal League performances specifically reflected the importance of the highest attack effectiveness when playing at home, during match period 9 when the opposing team had 3 fouls. However, attack effectiveness was lower during balanced matches when teams used attack durations ranging from 1-23s. In addition, the clustering technique (two-step cluster) allowed identification of the attack profiles in numerical superiority according to contextual variable importance and goal effectiveness with four different clusters. Each cluster showed specific profiles of attack contexts with one cluster associated with no goals (cluster 2 with $100 \%$ of no goal situations) and another related to a higher probability of scoring a goal (cluster 3 with $55.9 \%$ of no goal situations).
Further research should be developed in other leagues to sustain or refute the obtained results.

\section{Practical implications and limitations}

The identified trends are of great relevance from the coach's point of view where the numerical superiority/inferiority context of play directly impacts the team's performance. These scenarios should be carefully trained for and controlled as they occur in competition (i.e., manipulating match periods, attacking team fouls, opponent team fouls and match status), allowing coaches to give immediate feedback and the key instruction to players in order to improve their performance in numerical superiority/inferiority situations (Sarmento et al., 2015). Accordingly, from a practical application point of view, training tactics and strategies should replicate these scenarios with adaptations to different defensive formations using inferiority (Gk+ 4-v-3+GK); in opposition, the defensive formations may replicate a balanced situation using the goalkeeper as a player during the 2-min periods immediately after the dismissal (Gk+ 4-v-4+ GK) (Travassos et al., 2017).

The present study has some limitations that need to be addressed in future. Firstly, this study only accounts for the Gk + 4-v-3+ GK dismissal attacks. Due to the reduced number of attack situations during the regular season (only 4 attacks) of the 5-v-3+ GK match scenario, it was removed from the analysis. Therefore, the analysis of this specific playing superiority should be studied and compared with the most common superiority contexts in Futsal (Gk+ 4-v-3+ GK, 5-v-4-GK, and $5-v-3+$ GK). Secondly, further research should take into account specific match-related variables that would allow a better understanding of goal effectiveness such as offensive (e.g., number of passes, number of players involved or type of shots) and defensive (distances between defenders and attackers, zones of the court or type of defensive system) behaviours. Thirdly, the analysis of other contextual variables (e.g., impact of player's dismissal during knockout stages/playoffs or in international competitions) is relevant to identify the impact of dismissals in elite futsal. Lastly, the analysis of coaches' and players' points of view would give a subjective and psychological approach to the numerical superiority/inferiority situations during a match.

\section{Disclosure statement}

No potential conflict of interest was reported by the authors.

\section{ORCID}

Miguel A. Gómez (DD http://orcid.org/0000-0002-9585-3158

César Méndez (D) http://orcid.org/0000-0003-1662-2448

Bruno Travassos (iD http://orcid.org/0000-0002-2165-2687

\section{References}

Altman, D. G. (1991). Some common problems in medical research. In D. G. Altman (Ed.), Practical statistics for medical research (pp. 403-409). London: Chapman \& Hall. 
Barbero-Alvarez, J. C., Soto, V. M., Barbero-Alvarez, V., \& Granda-Vera, J. (2008). Match analysis and heart rate of futsal players during competition. Journal of Sports Sciences, 26(1), 63-73.

Bar-Eli, M., \& Tractinsky, N. (2000). Criticality of game situations and decision making in basketball: An application of performance crisis perspective. Psychology of Sport and Exercise, 1(1), 27-39.

Beato, M., Coratella, G., \& Schena, F. (2016). Brief review of the state of art in futsal. Journal of Sports Medicine and Physical Fitness, 56(4), 428-432.

Bray, S. R., Jones, M. V., \& Owen, S. (2002). The influence of competition location on athletes' psychological states. Journal of Sport Behavior, 25 (3), 231.

Castagna, C., D'Ottavio, S., Vera, J. G., \& Álvarez, J. C. B. (2009). Match demands of professional Futsal: A case study. Journal of Science and Medicine in Sport, 12(4), 490-494.

Corrêa, U. C., Davids, K., Silva, S. L., Denardi, R. A., \& Tani, G. (2014). The influence of a goalkeeper as an outfield player on defensive subsystems in futsal. Advances in Physical Education, 2014. doi:10.4236/ ape.2014.42012

Ferreira-da-Silva, D. (2011). Situações de superioridade numérica ofensiva no Futsal. Estudo de padrões de jogo com recurso à análise Sequêncial (Dissertação de Mestrado). Faculdade de Ciências do Desporto e de Educação Física. Universidade do Porto, Porto.

FIFA. (2014/2015). FUTSAL laws of the game. Retrieved from http:// resources.fifa.com/mm/document/footballdevelopment/refereeing/51/ 44/50/lawsofthegamefutsal2014_15_eneu_neutral.pdf

Gómez, M. A., Lorenzo, A., Ibanez, S. J., \& Sampaio, J. (2013). Ball possession effectiveness in men's and women's elite basketball according to situational variables in different game periods. Journal of Sport Sciences, 31(14), 1578-1587.

Gómez, M. A., Moral, J., \& Lago-Peñas, C. (2015). Multivariate analysis of ball possessions effectiveness in elite futsal. Journal of Sports Sciences, 33(20), 2173-2181.

Hill, D. M., \& Shaw, G. (2013). A qualitative examination of choking under pressure in team sport. Psychology of Sport and Exercise, 14(1), 103-110.

Lago-Peñas, C., Gómez-Ruano, M. A., Owen, A. L., \& Sampaio, J. (2016). The effects of a player dismissal on competitive technical match performance. International Journal of Performance Analysis in Sport, 16(3), 792-800.

Landau, S., \& Everitt, B. (2004). A handbook of statistical analyses using SPSS. Florida: Chapman \& Hall/CRD.

Leão, D. (2010). Incidência de gols em partidas que ocorrem situações de inferioridade e superioridade numérica em função da expulsão no futsal. RBFF-Revista Brasileira de Futsal e Futebol, 2(6), 10.

Lupo, C., Tessitore, A., Minganti, C., \& Capranica, L. (2010). Notational analysis of elite and sub-elite water polo matches. The Journal of Strength \& Conditioning Research, 24(1), 223-229.
Marcelino, R., Mesquita, I., \& Sampaio, J. (2011). Effects of quality of opposition and match status on technical and tactical performances in elite volleyball. Journal of Sport Sciences, 29, 733-741.

Oliveira, T., Gómez, M., \& Sampaio, J. (2012). Effects of game location, period, and quality of opposition in elite handball performances. Perceptual and Motor Skills, 114(3), 783-794.

Prieto, J., Gómez, M. Á., \& Sampaio, J. (2015). Players' exclusions effects on elite handball teams' scoring performance during close games. International Journal of Performance Analysis in Sport, 15(3), 983-996.

Sarmento, H., Bradley, P., Anguera, M. T., Polido, T., Resende, R., \& Campaniço, J. (2016). Quantifying the offensive sequences that result in goals in elite futsal matches. Journal of Sports Sciences, 34(7), 621629.

Sarmento, H., Bradley, P., \& Travassos, B. (2015). The transition from match analysis to intervention: Optimising the coaching process in elite futsal. International Journal of Performance Analysis in Sport, 15(2), 471-488.

Sarmento, H., Marcelino, R., Anguera, M. T., Campaniço, J., Matos, N., \& Leitão, J. C. (2014). Match analysis in football: A systematic review. Journal of Sports Sciences, 32(20), 1831-1843.

Tabachnick, B. G., \& Fidell, L. S. (2007). Multivariate analysis of variance and covariance. Using multivariate statistics (pp. 402-407). Boston, MA: Allyn $\&$ Bacon.

Travassos, B., Araújo, D., Duarte, R., \& McGarry, T. (2012). Spatiotemporal coordination patterns in futsal (indoor football) are guided by informational game constraints. Human Movement Science, 31, 932-945.

Travassos, B., Vilar, L., Araújo, D., \& McGarry, T. (2014). Tactical performance changes with equal vs unequal numbers of players in small-sided football games. International Journal of Performance Analysis in Sport, 14(2), 594-605.

Travassos, B., Bourbousson, J., Esteves, P. T., Marcelino, R., Pacheco, M., \& Davids, K. (2016). Adaptive behaviours of attacking futsal teams to opposition defensive formations. Human Movement Science, 47, 98-105.

Vicente-Vila, P., \& Lago-Peñas, C. (2016). The goalkeeper influence on ball possession effectiveness in futsal. Journal of Human Kinetics, 51(1), 217224. doi:10.1515/hukin-2015-0185

Vilar, L., Araújo, D., Davids, K., Correia, V., \& Esteves, P. T. (2013). Spatial-temporal constraints on decision-making during shooting performance in the team sport of futsal. Journal of Sports Sciences, 31(8), 840-846.

Volker, M. A. (2006). Reporting effect size estimates in school psychology research. Psychology in the Schools, 43(6), 653-672.

Willoughby, K. A. (2002). Winning games in Canadian football: A logistic regression analysis. The College Mathematics Journal, 33(3), 215-220. 